\title{
2-D Numerical Model of the Impact of Circulating Water Intake-drainage Project in Power Station.
}

\author{
X.Z. ZHANG \& X.P. DOU \& L. DING \& J. JIAO \& Z.X. JIAO \\ Nanjing Hydraulic Research Institute, Key Lab of Port \\ Waterway and Sedimentation Engineering of the Ministry of Transport, Nanjing, China
}

\begin{abstract}
KEYWORDS: NUMERICAL MODEL, ENGINEERING, PIPELINE PROJECT
ABSTRACT: Circulating water intake-drainage project is an important part in Power Station. The difference of circulating water quantity and intake-drainage method has various impacts on the circulating water intake-drainage project. Flow field variation of different water drainage projects (drainage by and open canal and pipeline) is analyzed by 2-D numerical model in this paper. The result shows that, drainage project by open canal and pipeline only have effect on flow field in area near the project and the influence of open canal is more severe but under this project, warm water can mix with water of bottomland sufficiently the influence on the intake is weaken.
\end{abstract}

\section{INTRODUCTION}

Thermal power plant generates electricity by burning of fossil fuels like coal, oil and its products, natural gas, etc. Waste heat produced during power generating need to be carried out by cooling water. Circulating water pump house uses water from river and sea as cooling water. Cooling device takes in waste heat making the water temperature higher and then drains off into the river and sea. Cooling water circulates in power plant and river and sea by circulating water intake-drainage project and guarantees the security of power plant. The difference of intake-drainage methods has various impacts on the flow field. Taking Kenya Lamu Power Plant into consideration, flow field variation of different water drainage projects (drainage by and open canal and pipeline) is calculated. Research results provide a reference for similar engineering construction.

Kenya Lamu Power Plant uses sea water as cooling water. Circulating water pump house intake sea water by pipeline. Drainage by open canal and pipeline is preliminary designed. The elevation of water intake is $-10.0 \mathrm{~m}$. The distance between drain outlet and power plant is $1600 \mathrm{~m}$ and the elevation of drain outlet is $-4 \mathrm{~m}$. In pipeline drainage project, each generator unit has a DN2600 drain pipeline and an $8 \mathrm{~m} \times 6 \mathrm{~m} \times 8 \mathrm{~m}$ rectangle drain outlet. In open canal drainage project, trapezoidal cross-section is used, the bottom width is $4 \mathrm{~m}$, bottom slope is 0.003 and slope coefficient is 1:2.5. The temperature rise of the drainage is $9{ }^{\circ} \mathrm{C}$ and the discharge is $35 \mathrm{~m}^{3} / \mathrm{s}$. The coal wharf of power plant is located at upstream of intake with the distance about $400 \mathrm{~m}$. The elevation of seabed before the wharf is $-8.8 \mathrm{~m} \sim-9.6 \mathrm{~m}$. Figure1 shows the detail of engineering layout. 


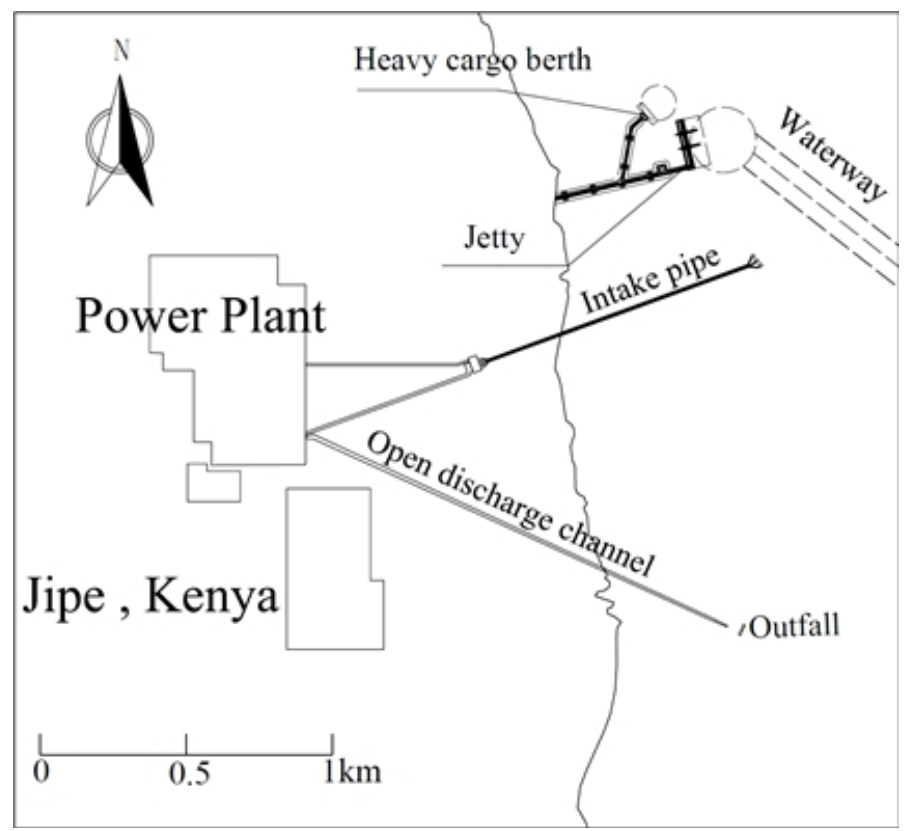

Figure 1. Engineering layout

\section{ESTABLISHMENT AND VERIFICATION OF NUMERICAL MODEL}

\section{2-D tide movement fundamental equation}

2-D tide movement fundamental equation in coast and estuary can be shown as:

(1) The continuous equation

$$
\frac{\partial Z}{\partial t}+\frac{\partial H u}{\partial x} \frac{\partial H v}{\partial y}=q
$$

(2) The momentum equation

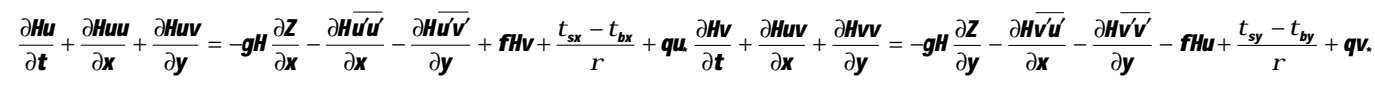

In this equation, $u$ and $v$ represent the velocity component in the direction of $\xi$ and $\eta \ldots Z$ is the water level. $H$ is the depth of water. $C$ is Chezy coefficient. $f=2 \omega \sin \varphi$ is the Coriolis force coefficient. ( $\omega$ is rotational angular velocity of the earth). $q$ is intensity of source and a sink in a unit area. $u$ and $v$ represent the velocity component in the direction of $\xi$ and $\eta$ around nodes. $\left(\tau_{s x}, \tau_{s y}\right)$ represents wind-stress above water surface. $\left(\tau_{b x}, \tau_{b y}\right)$ represents stress of bed resistance. 2D Flow movement fundamental equation can be solved by finite- difference discrete and TDMA.

Study area and grid

The area studied by numerical model is $54.5 \mathrm{~km}$ (from East to West) $\times 84 \mathrm{~km}$ (from North to South). Unequal grid is adopted during mesh generation in the study area. The grid number is $430 \times 473$, the grid near project is made more intensive near project. The minimum grid scale is $2 \mathrm{~m}$

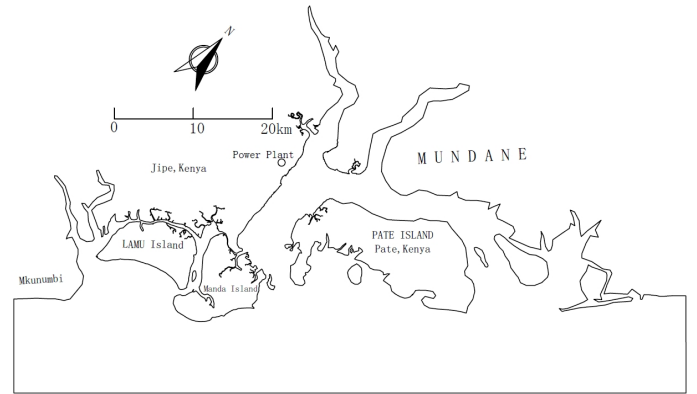

Figure 2. Study area of the Numerical Model 


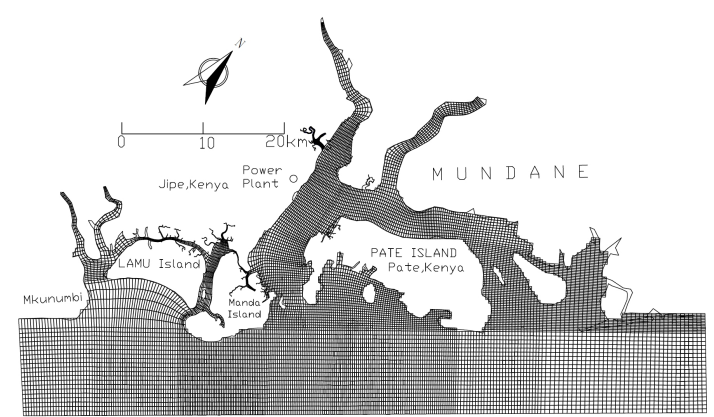

Figure 3. Grid of the Numerical Model

\section{D numerical model validation}

Tidal numerical model validated by the measured data near engineering area (Figure 4 Figure 6 ). The validation shows that water tide level and velocity process fit the measured data well and can better reflect characteristic of flow field of sea around engineering project. Figure 7 shows local flow status near engineering area.

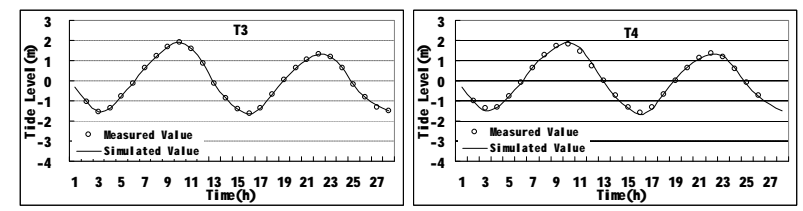

Figure 4 Tide level validation

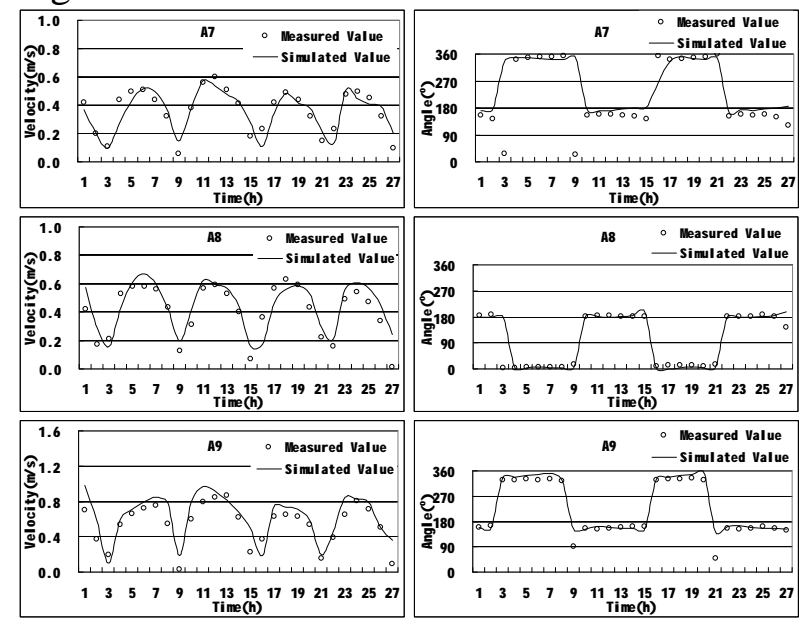

Figure 5 Validation of the velocity and direction of flow

\section{IMPACT OF ENGINEERING}

Figure 6 shows the flow field chart near drain outlet in pipeline drainage project. From this picture we find the flow chart is only slightly affected in pipeline drainage project. When velocity is larger during flood tide and ebb tide. The flow field near drain outlet changes a little and the direction of flow changes for the effect of drainage. During high water level and low water level, as velocity is smaller during flood tide and ebb tide, diverging flow takes place near drain outlet which shows the change of flow field when cooling water discharge. Pipeline drainage project has little effect on surrounding flow field, however, cooling water running into deep water mixed upstream and downstream by tide flow. Especially during flood tide, it can flow to water intake easily and influence the water intaking. 


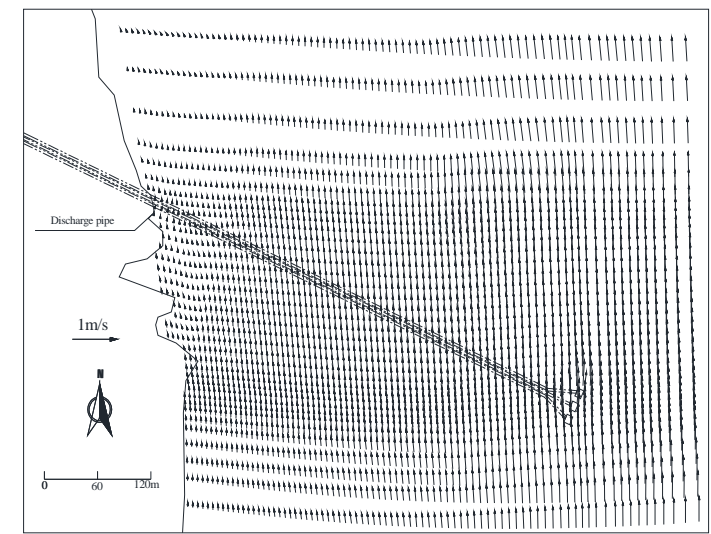

(a) maximum flood

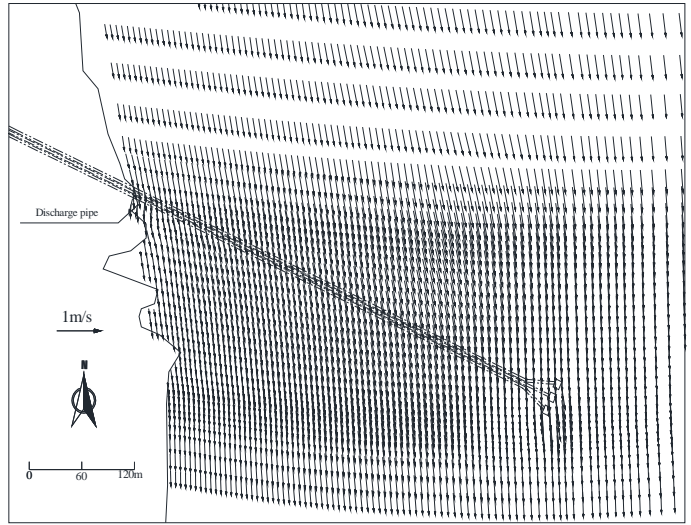

(b) maximum ebb

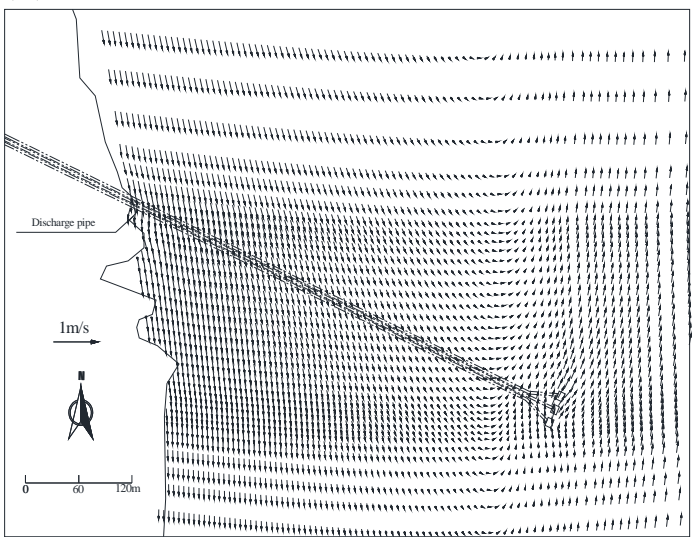

(c) maximum tide level

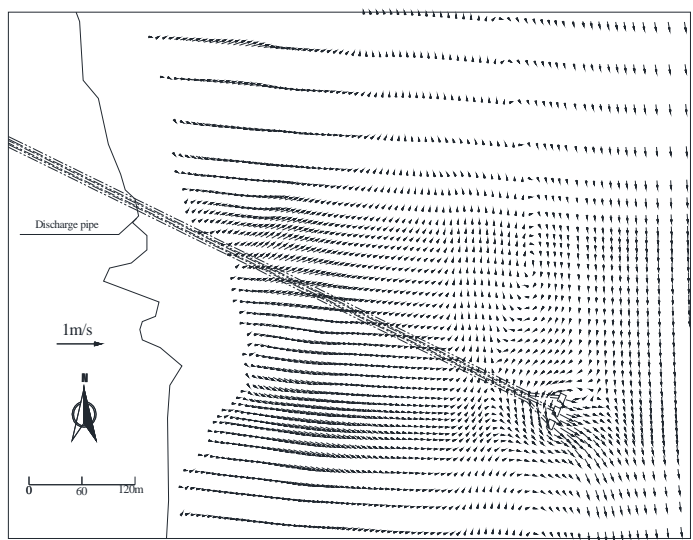

(d) minimum tide level

Figure 6 Flow regime near drain outlet in pipeline drainage project 
Figure 7 shows the flow field chart near drain outlet in open canal project. When water level is relatively high, open canal is covered by water and tide come through open canal. The flow regime near the entrance of open canal changes a lot while the change near the outlet of open canal changes is not obvious. When the water level is relatively low, water can run through open canal to outlet. Overbank flow is obvious in the entrance of open channel while flow path is distinct in the exit of open channel. Recirculation zone appears upstream and downstream the water outlet. According to the changes of flow regime in different time, floodplain flow from the entrance to the exit of open canal changes a lot and this can mix the hot water discharged from the plant with the floodplain water well and weaken the influence on the water intake.

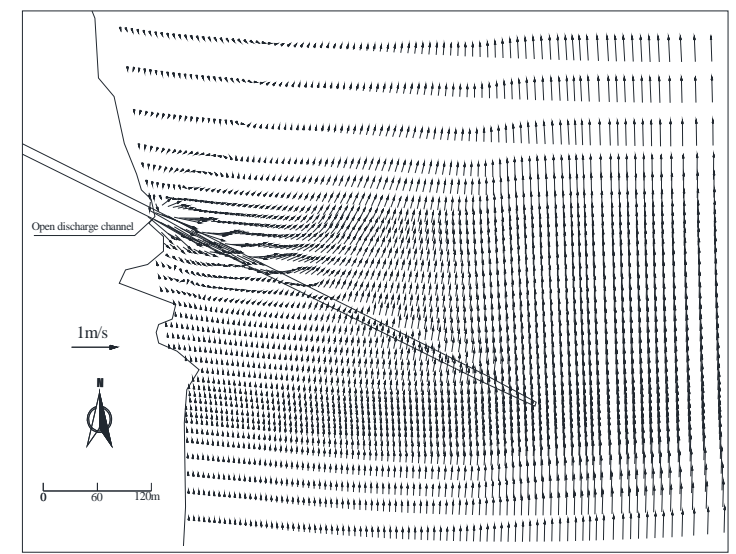

(a) maximum flood

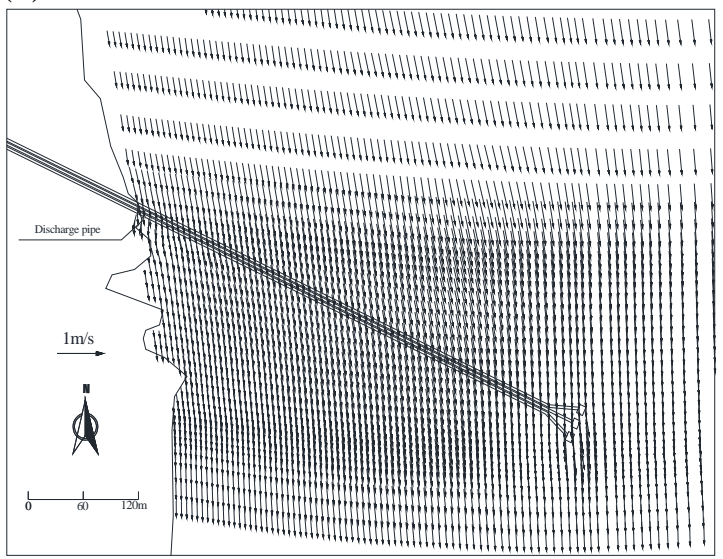

(b) maximum ebb

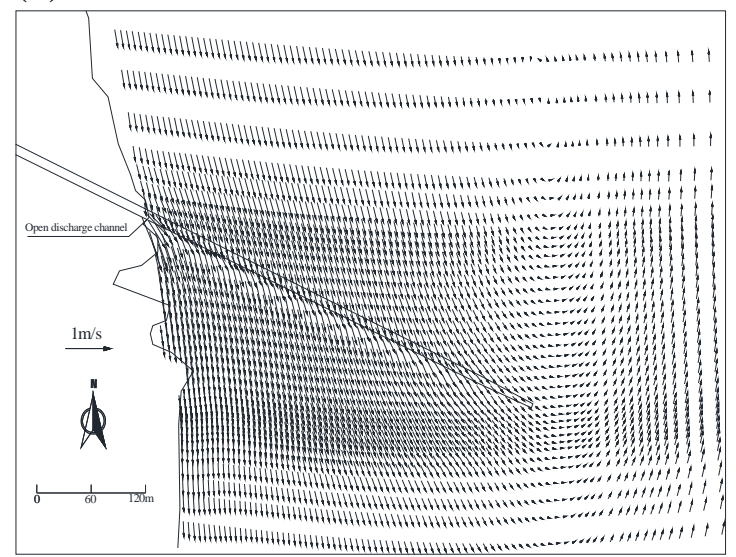

(c) maximum tide level 


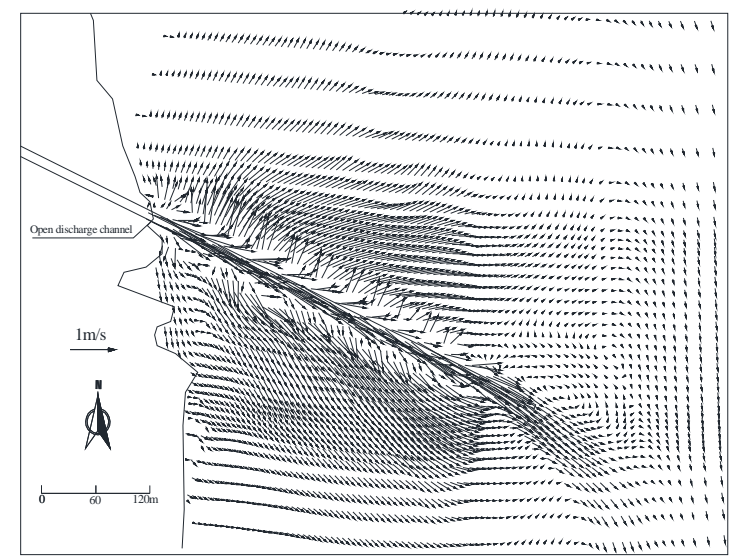

(d) minimum tide level

Figure 7 Flow regime near drain outlet in open channel project

Figure 8 envelope diagram of velocity change before and after the pipeline and open canal project As shown in Figure 8, flow field variation caused by engineering only appears near them. Variation range of velocity is relatively small in pipeline project. The southern-most area which velocity $0.01 \mathrm{~m} / \mathrm{s}$ appears is $1.2 \mathrm{~km}$ away from exit of pipeline. Variation range of velocity is relatively large in open canal project. The southern-most area which velocity $0.01 \mathrm{~m} / \mathrm{s}$ appears is $1.6 \mathrm{~km}$ away from exit of open canal. Variation range of velocity $0.05 \mathrm{~m} / \mathrm{s}$ and $0.10 \mathrm{~m} / \mathrm{s}$ in open canal project is apparently larger than that in pipeline project.
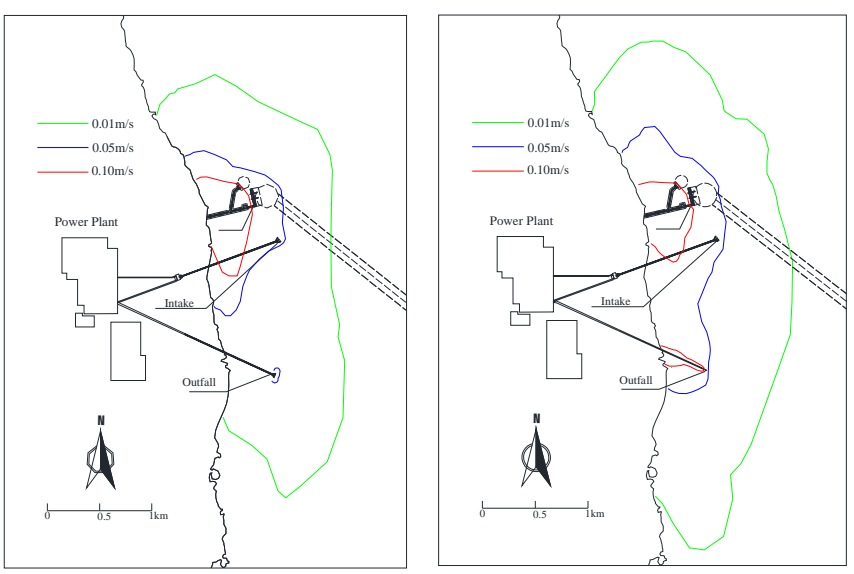

(a) pipeline drainage project (b) open channel project

Figure 8 envelope diagram of velocity change before and after the project

\section{CONCLUSION}

The calculation of tidal numerical model shows that the construction of pier and drainage engineering project only has effect on the flow field near the engineering.

(1) According to the variation of flow field, the influence of open canal project is much larger than that of pipeline project.

(2) According to hot water diffusion, open canal avoid hot water running into deep water directly and flow to water intake with flood tide current. Hot water can mix the floodplain flow well which reduce the bad influence on water intake.

(3) Comparing two projects, if the influence on the flow field is limited and have no huge effect on dock and navigation of the ship, open canal project can reduce the influence on the water intake. 


\section{ACKNOWLEDGEMENTS}

The project is financially supported by Ministry of Transport major special science and technology projects of China (Grant No. 201132874640) and National Science Foundation No. 51409163.

\section{REFERENCE}

Li, T.L \& Gao, X.Y. etc. 2010. Numerical simulation of Cooling Water in Jiangsu Huayang Chenjia Port Power Plant(Chinese).

Zhang, S.N. 1988. Environmental Hydraulics. Hohai University Press.

Liu, L. F. Hao, H., \& Guang-Si, L. U. 2004. Experiment study on attenuation law of residual chlorine in cooling water discharged from thermal power plants. Journal of Hydraulic Engineering. 